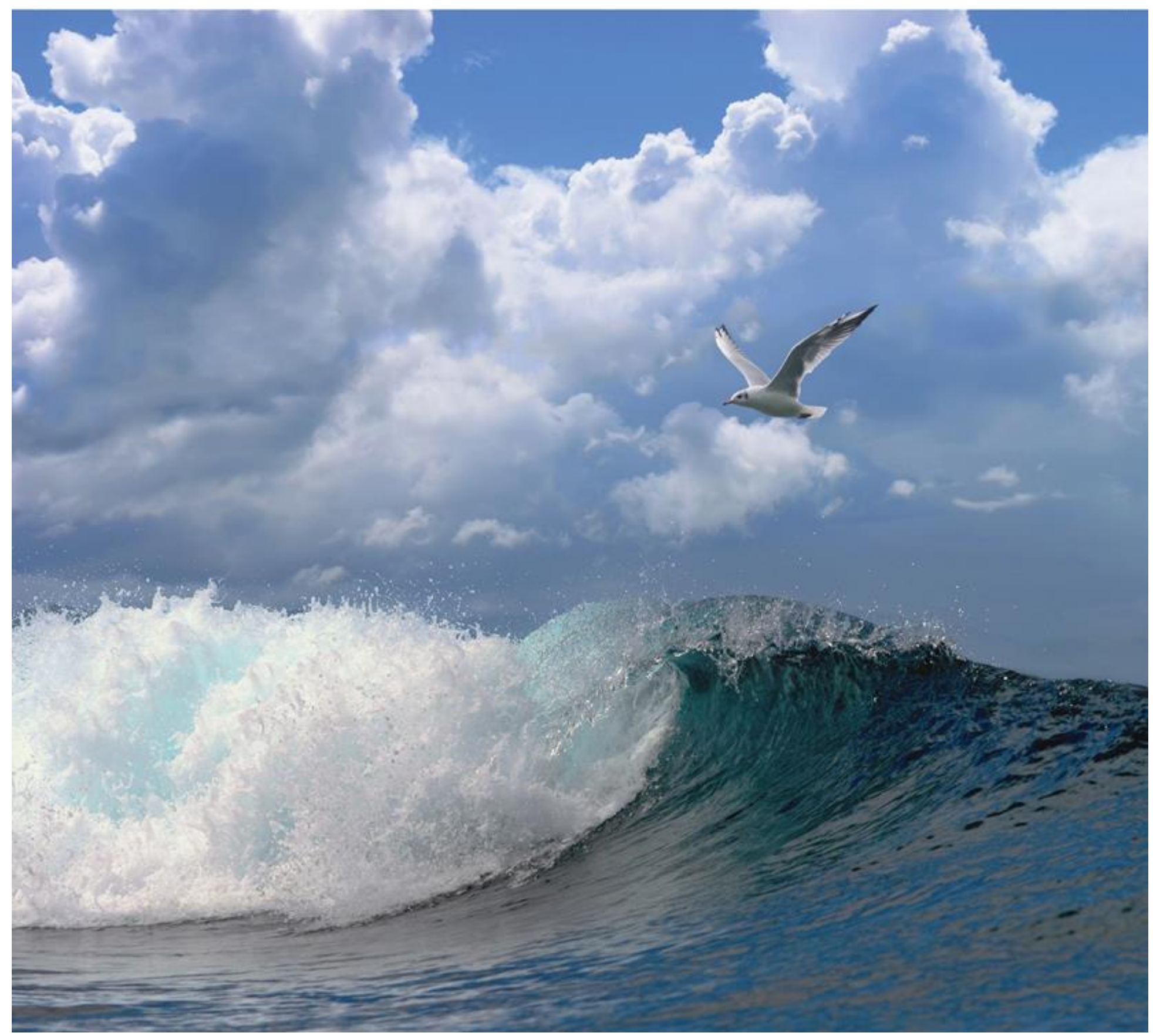

Fishing activity near offshore pipelines, 2017 


\section{Fishing activity near offshore pipelines, 2017}

Author: Marcel Machiels

Publication date: January 2018 
Marcel Machiels, 2018. Fishing activity near offshore pipelines, 2017; . Wageningen, Wageningen Marine Research (University \& Research centre), Wageningen Marine Research report reportnumber C016/18. 19 pp.

Keywords: Offshore Pipeline; Trawling Fishery Factor; Risk- \& Probability Analysis.

Client: $\quad$ Fugro Survey B.V.

Attn.: Dhr B. Possel

Veurse Achterweg 12, P.O. Box 128

2260 AC, Leidschendam

This report can be downloaded for free from https:// doi.org/10.18174/443945

Wageningen Marine Research provides no printed copies of reports.

Wageningen Marine Research is ISO 9001:2008 certified.

(c) 2018 Wageningen Marine Research Wageningen UR

Wageningen Marine Research The Management of Wageningen Marine Research is not responsible for resulting institute of Stichting Wageningen damage, as well as for damage resulting from the application of results or Research is registered in the Dutch research obtained by Wageningen Marine Research, its clients or any claims traderecord nr. 09098104, related to the application of information found within its research. This report BTW nr. NL 806511618 has been made on the request of the client and is wholly the client's property. This report may not be reproduced and/or published partially or in its entirety without the express written consent of the client.

A_4_3_2 V25 


\section{Contents}

$\begin{array}{lr}\text { Summary } & 4\end{array}$

$\begin{array}{llr}1 & \text { Introduction } & 5\end{array}$

2 Assignment $\quad 6$

$3 \quad$ Materials and Methods $\quad 7$

$4 \quad$ Results $\quad 11$

$5 \quad$ Conclusions and recommendations $\quad 15$

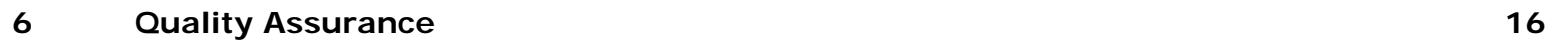

$\begin{array}{lr}\text { References } & 17\end{array}$

$\begin{array}{lr}\text { J ustification } & 18\end{array}$ 


\section{Summary}

On the North Sea bottom lie numerous pipelines to link oil- or gas offshore drilling units, - platforms and processing stations on land. Although pipeline tubes are coated and covered with protective layers, the pipelines risk being damaged through man-made hazards like anchor dropping and fishing activities with bottom trawls.

Fugro Survey B.V. works towards integrated risk assessment of pipelines for amongst others TAQA Energy B.V. Spatial maps of fishing activity would contribute to this risk assessment. Therefore, WMR was tasked to quantify the amount of fishing activity in the vicinity of TAQA Energy B.V. pipelines. Fishing activity has been quantified at a spatial scale of approximate $3800 \mathrm{~m}^{2}$ blocks (68m by $56 \mathrm{~m}$ ) using fishing Vessel Monitoring System (VMS) data in 2017 (1/10/2016-30/9/2017).

The results in this study show that small beam-trawling vessels are active within, and just outside the 12 mile zone around the pipelines. In total, between 0 and 8.7 minutes per year of trawling is accumulated over the whole period within each spatial block. For the larger beam-trawlers, only present outside the 12 mile zone, in total between 0 and 1.8 minutes per block and year of trawling is accumulated. A conversion of these numbers to fishing intensity, a measure for number of times a block is fully trawled, shows that sections of the pipeline are trawled between 0 and 3.4 times a year. This fishing intensity is below the range of 5-10 times a year estimated in the most intensively fished areas of the North Sea.

The indicators calculated in this study, reflecting number of potential interactions (fishing effort) of trawling vessels with the pipelines and the potential severity of these interactions (fishing intensity), may contribute to the risk assessment. It should be noted, however, that owing to seasonal changes in fish distribution and yearly changes in fishing gear characteristics, these maps do not provide an accurate base for the prediction of future fishing impact. 


\section{Introduction}

On the North Sea bottom lie numerous pipelines to link oil- or gas offshore drilling units, - platforms and processing stations on land. Although pipeline tubes are coated and covered with protective layers, the pipelines risk being damaged through man-made hazards like anchor dropping and fishing activities with bottom trawls. Although positions of most pipelines are known (position of older pipelines may be less accurate) an avoidance strategy of the fishing fleet is lacking. Over the past decades, around thirty hits by fishing gear were recorded that resulted in pipeline leaks. Each leak caused by a hit by fishing gear may be associated with substantial environmental and economic risks. Identifying these risks may therefore be important in the overall risk assessment of offshore oil- and gas production activities.

I dentifying where fishing operations are most dominant around pipeline tracks at the sea bottom can support additional and better targeted surveying operations, executed by Fugro, to check the integrity of pipelines. Survey results may, in combination with risks of fishing impact, result in tailored approaches to further protect pipelines from impacts or improve the design and position of new pipelines.

After a study on fishing intensity near pipelines in 2015 and 2016 (Hintzen and Machiels, 2017) Fugro requested WMR to investigate bottom fishing activity of the Dutch fishing fleet near TAQA Energy B.V. pipelines based on VMS (Vessel Monitoring by Satellite) information, giving information on the spatial and temporal distribution of fishing vessel activities during 2017.

This study provides maps and shape files of fishing intensities of 2017 (October 2016-October 2017) in a buffer area around the pipelines that can be used in a GIS application by Fugro to assess risks and advise TAQA Energy B.V. on, for instance, additional survey activities. The addition of a fishing intensity layer to the procedure currently applied by Fugro may improve the overall risk assessment for pipeline damages. 


\section{Assignment}

Within this study, we quantify the amount of fishing effort that is allocated at, or close to, a selection of pipelines by Dutch bottom fishing vessels. In the quantification, measures of uncertainty in the data collected that represents fishing activity, are directly implemented. The final product is a shape file for the period October 2016 - October 2017, containing the pipeline trajectories including a buffer area, and the associated fishing effort and -intensity within these areas at a aggregation level of $3800 \mathrm{~m}^{2}$ $(68 \mathrm{~m} * 56 \mathrm{~m})$ grid cells. 


\section{$3 \quad$ Materials and Methods}

Since the 1st of January 2005 all fishing vessels larger than 15 meters are equipped with VMS and since the 1st of January 2012 the on-board VMS-obligation concerns all vessels larger than 12 meters. A VMS transponder sends at regular intervals a signal to a satellite providing information on the vessel's ID, position, time $\&$ date, direction and speed. Hence, VMS is a useful data source to study the distribution of the fishing fleet both in time and space. The Dutch ministry of Economic Affairs is tasked with the collection of VMS data of all Dutch fishing vessels. VMS data of foreign vessels, even inside the EEZ, are made irregularly available for scientific purposes. All VMS positions are collected in the WGS84 reference coordinate system.

As VMS signals lack any information on the activities of the fisheries itself, e.g. regarding fishing gear, catch composition, departure harbour or vessel dimensions, for many fisheries related studies, VMS is coupled to fisheries logbooks. These logbooks report per fishing trip (approx. 2 - 5 days) when fishermen leave harbour, what gear has been used to fish, their catch composition and a rough estimate of the location of the catches for each 24 hour period. Both VMS and logbook data report on the fishing vessel ID, which allows for the coupling of the two datasets and study fisheries distribution at finer spatial and temporal scales.

A summary of the VMS- data-processing starting with pre-process, analyse VMS- and logbook data, combine these datasets and link gear specific effort to the pipelines is given below. A more detailed description on the processing and assumptions made during this process can be found in Hintzen et al. (2013); http://edepot.wur. $\mathrm{nl} / 248628$.

Data pre-processing:

- $\quad$ VMS and logbook data are received from the Ministry of LNV and stored in a local database at WMR.

- VMS records are considered invalid and therefore removed from the analyses when they:

o are duplicates or pseudo-duplicates (indication of malfunctioning of VMS device)

o identify an invalid geographical position

o are located in a harbour

o are located on land

o $\quad$ are associated with vessel speeds $>20$ knots

o logbook records are removed from the analyses when they:

o are duplicates

o have arrival date-times before departure date-times

o overlap with other trips

Link VMS and logbook data:

- $\quad$ VMS and logbook datasets are linked using the unique vessel identifier and date-time stamp in both datasets available. In other words, records in the VMS dataset that fall within the departure-arrival timeframe of a trip described in the logbook are assigned the unique trip number from the logbook record which allows matching both datasets

- $\quad$ Fishing trips, using bottom gear types like beam trawlers (referred to with code TBB), otter trawlers (OTB), dredges (DRB and HMD) \& Scottish seines (SSC), showing VMS signals around the pipelines track [ between latitudes 51.7 and 52.6; longitudes 3.2 and 4.6] are selected (gears such as gillnets or midwater trawls are not taken into account given their limited to non-existing contact with the seabed when in operation).

- Only VMS and logbook data of the time period 10/2016-09/2017 are used.

Define fishing activity:

- $\quad$ Speed recordings obtained from VMS data are used to create frequency plots of these speeds, where along the horizontal axis the speed in knots is given and the vertical axis denotes the 
number of times that speed was recorded. In general, 3 peaks can be distinguished in such a frequency plot. A peak near 0 knots, associated with being in harbour/floating, a peak around the average fishing speed and a peak around the average steaming speed. These analyses are performed separately per gear type for two kW classes $(<=225 \mathrm{~kW}$ and $>225 \mathrm{~kW}$ ) as these vessel types show different fishing behaviour and are allowed to fish in different regions.

- According to the method described above, a number of VMS records can be associated with fishing activity, depending on the gear used by the vessel. In general, vessel speeds between 1.5 and 8 knots are characterized as fishing. For small beam trawlers the selected range was approximately 2-7 knots. For large trawlers the range was approximately 4-8 knots.

Increase spatio-temporal resolution:

- VMS recordings are available for fishing vessels approximately every half hours. When the vessel speed is 4 knots, the trawling distance between two successive VMS locations, at $1 / 2$ hour pings intervals, is approximately $4 \mathrm{~km}$. Although on a yearly basis this amounts to a vast amount of spatial data, for studies such as the current one, additional detail is required to appropriately link a pipeline route to crossing fishing vessels activities. For this purpose, an interpolation routine is used which estimates intermediate locations between two successive VMS pings. The routine used in this study is described in detail in Hintzen et al., 2010. On average, an additional 700 points are added in between two successive VMS pings which are by default two hours apart, resulting in a dataset with pings intervals of 10 seconds.

Define area of interest:

- In total $61 \mathrm{~km}^{2}$ pipeline trajectories were identified that needed investigation in this study. They are located in the North Sea coast within the ICES rectangles 32-33/F3-F4 (see Figure 1). The study area has further been divided into small squares (a grid) of $\sim 68 \times 56 \mathrm{~m}$ blocks to allow for more detailed spatial analyses.

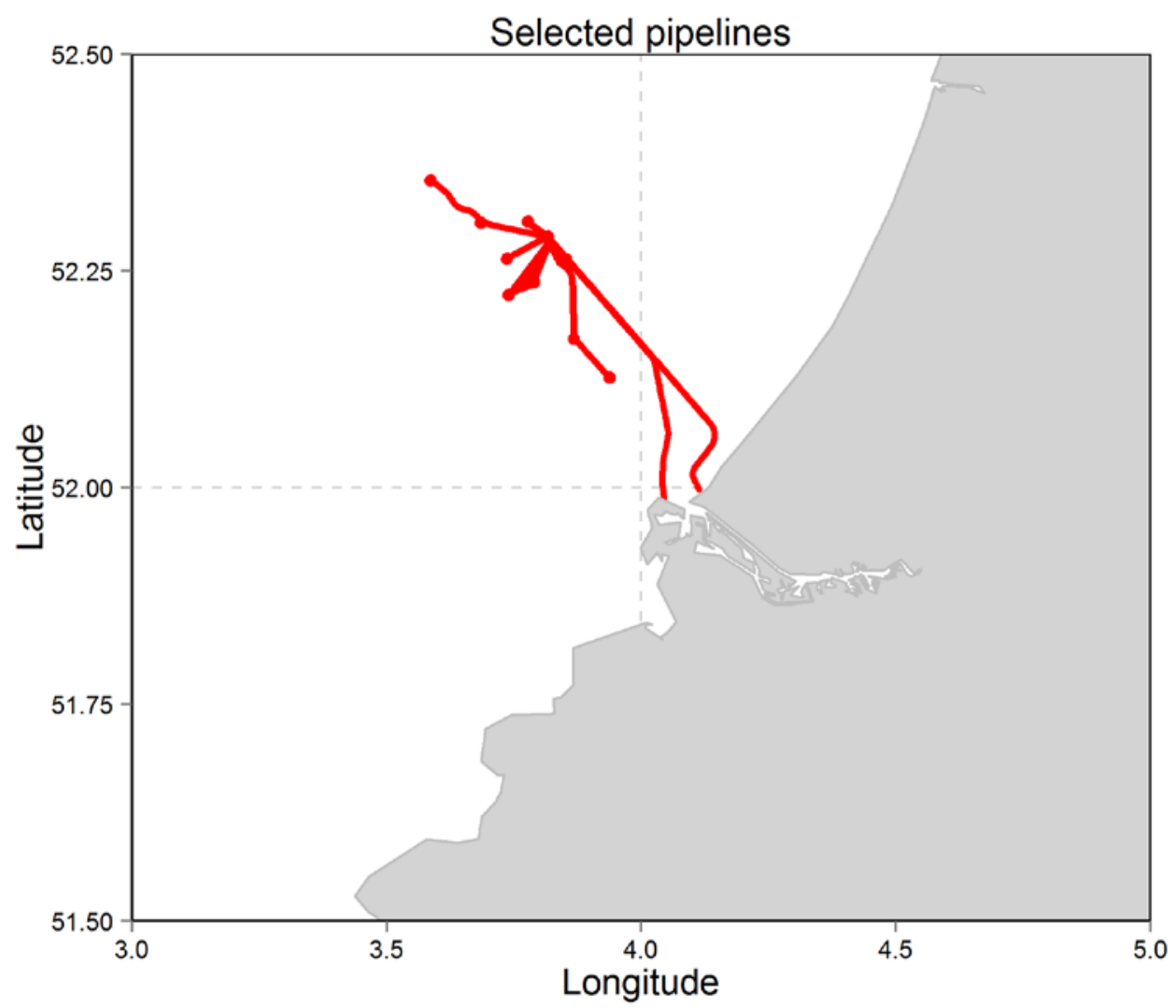

Figure 1. Dutch North Sea coast and locations of pipelines included a buffer area around pipelines (61 $\mathrm{km}^{2}$ ) overlaid with 3 ICES rectangles 33F3-4 \& 32F3 (bordered by grey straight dotted lines). 
Link pipeline location to fishing effort:

- We assume that a pipeline hazard may be caused by a build-up of smaller damage events caused by passages of active fishing vessels using bottom gears. The exact route of fishing vessels is however uncertain given that only every 2 hours exact vessel position data is collected and stored. Therefore, the increased spatio-temporal resolution improvements have to be made. This however, does not account for uncertainty in this interpolation method. Additionally we assume that activity is certain at the locations from which a VMS ping was send to the satellite, but certainty decreases in between these time stamps and decreases further away from the interpolated track. This together creates a 2-dimensional confidence interval for each fishing vessel movement, which can be scaled to represent the interval hours of fishing in total. Figure 2 gives a graphical representation of the interpolation and confidence interval calculation.

Note that each grid cell then represents a certain amount (measured in minutes) of fishing activity. This uncertainty is calculated assuming a grid of $68 \times 56 \mathrm{~m}$ blocks. By cumulating the fishing effort of all vessels of the fleet under consideration, the grid cell values reveal detailed spatial information of fishing activities during a year. By multiplying the fishing activity by gear with the fishing speed and gear width, and dividing by surface area of each grid cell, we calculate the fishing intensity. Finally, the pipeline location is overlaid onto the fishing activity grid to link the fishing effort to each pipeline location. A shape file is created containing the fishing activity by grid cell bounded by the pipeline trajectories.

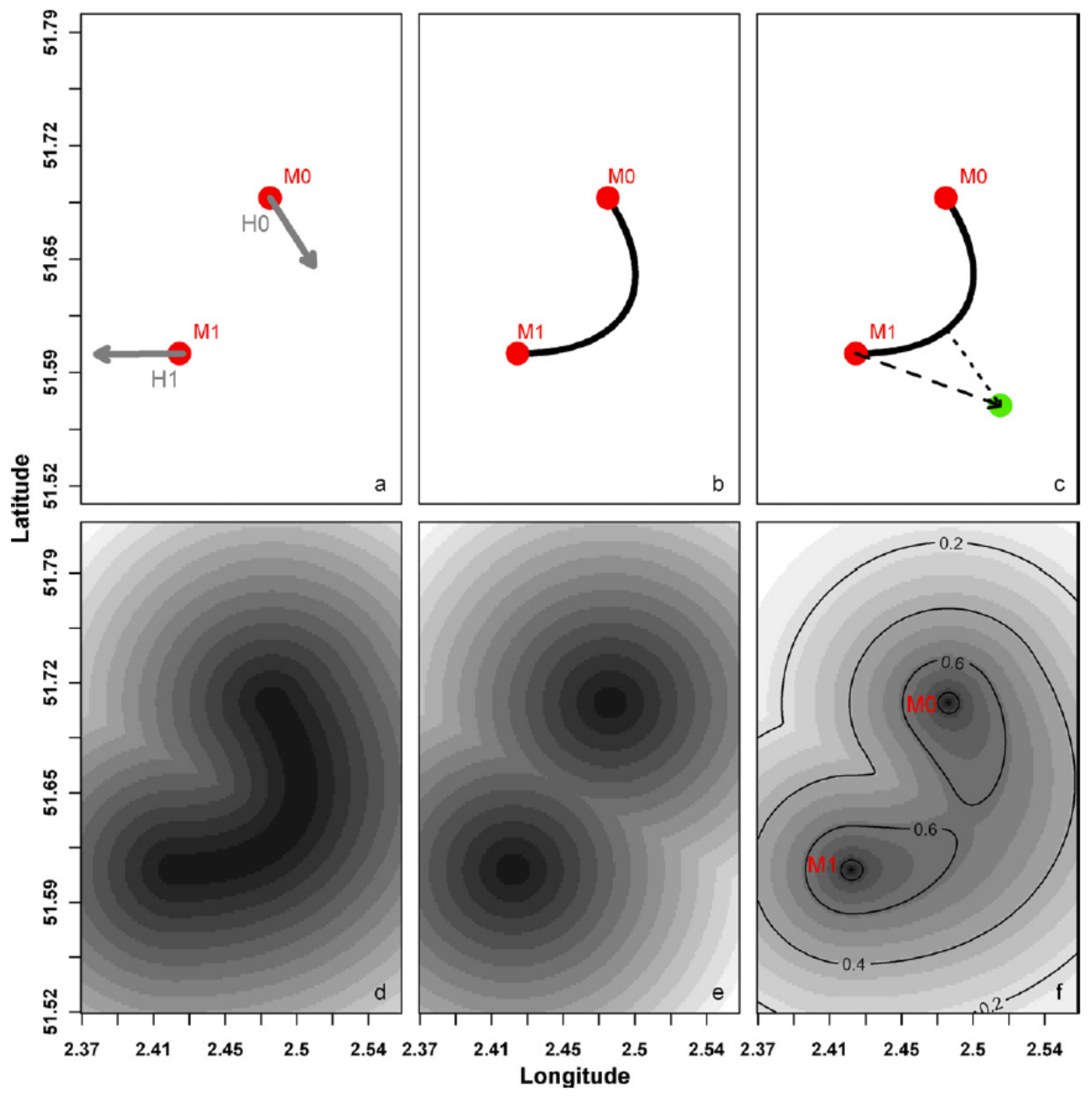

Figure 2. Schematic representation of the interpolation process starting with two succeeding VMS position registrations towards an estimated track surrounded by a confidence interval. (a) The start 
and end point of the vessel are represented by $M_{0}$ and $M_{1}$ respectively, the heading of the vessel at start- and end-point are represented by the small arrows $\mathrm{H}_{0}$ and $\mathrm{H}_{1}$. Based on the value of a scaling parameter these arrows become longer/shorter influencing the curvature of the interpolation (see panel b). For small values of this parameter, the interpolation will approximate a straight line between $M_{0}$ and $M_{1}$. (b) Interpolated track based on cubic Hermite spline (black solid line). (c) The parameter DSD for a random point on a grid (green dot) depends on the distance marked by the dashed arrow (black dashed arrow) from M1 to the green dot. (d) Shortest distance from each point on a grid to the interpolated track. Lighter grey represents more distant grid cells. (e) Shortest distance from each point on a grid to either M0 or M1. Lighter grey represents more distant grid cells. (f) Interpolation between two succeeding VMS data points surrounded by a confidence interval. At positions M0 and M1, values equal one. 


\section{$4 \quad$ Results}

The area of interest and pipeline trajectories, as provided by Fugro, is shown in Figure 1. ICES rectangles are squares of 1 degree longitude by 0.5 degrees latitude and follow a naming convention that covers the entire North East Atlantic. Fisheries logbook data is recorded at the ICES rectangle level. It is therefore that the study focusses on three ICES rectangles in the vicinity of the pipelines.

The Dutch fishing effort in the area of interest in 2016/2017 is mapped in figure 3. The colours used are shown in the palette below:

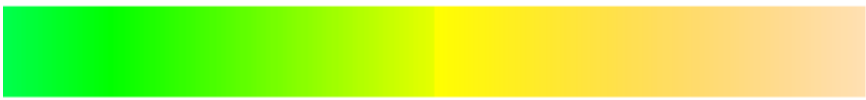

Green grid cells show the highest fishing effort or intensity and reduced yellow(ochre). The actual values are shown in the palettes right of the figures.

Figures $3 \& 4$ show fishing effort of all gears, the beam-trawlers separately and fishing intensity for all gears respectively. Fishing effort is given as total time (minutes) fishing vessels were fishing in grid block cells of $68 \mathrm{~m} \times 56 \mathrm{~m}$. Fishing intensity is given as the total number of times a grid cell is fully trawled, i.e. total area trawled per grid cell divided by the surface area of a grid cell.
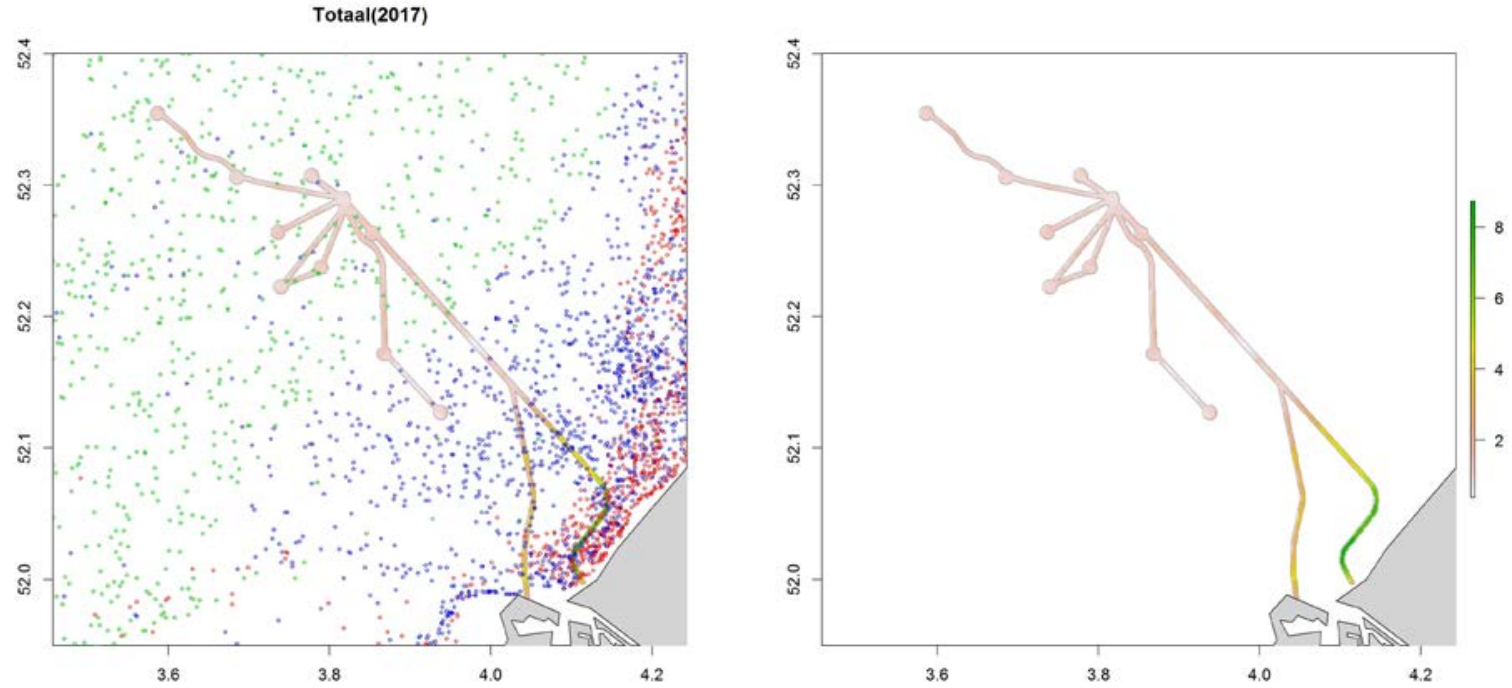

Figure 3. Fishing effort grid-map of all bottom gears in 2017. The grid cell dimensions are $68 * 56 \mathrm{~m}$ and the colour indicates the total amount of fishing effort in minutes (see palette). The buffer area around the pipelines are also shown (grey lines). Right figure includes a sample (10\%) of VMS pings recorded Pings that are scattered green indicates large pulse trawlers, blue small pulse trawlers and red shrimp trawlers. 

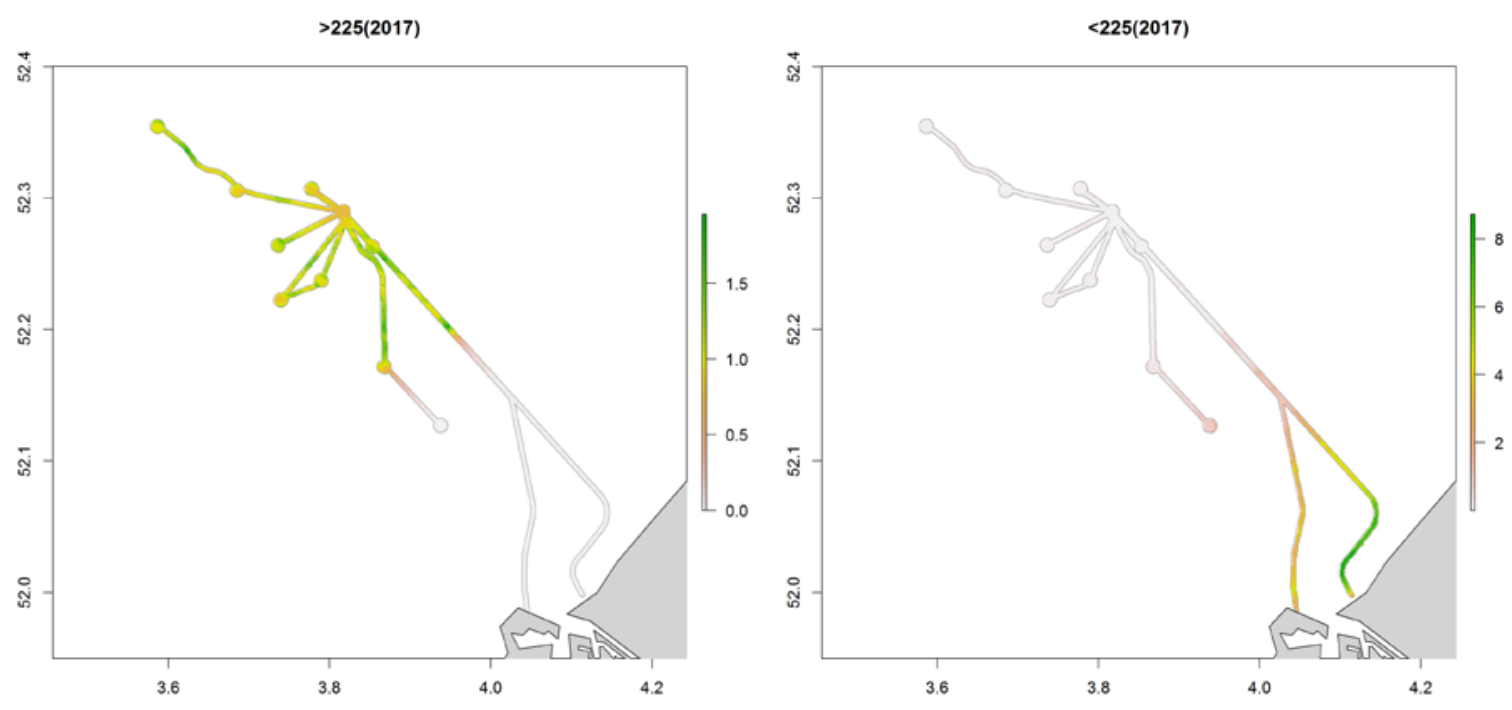

Figure 4. Fishing effort grid-map of [left] large bottom trawlers, including pulse - (TBB, >300hp, restricted to fish outside the 12 mile zone) and [right] small bottom trawlers, including pulse- $\&$ shrimp(TBB, <300hp) in 2017. The grid cell dimensions are 68*56 m and the colour indicates the total amount of trawling effort in minutes (see palette). The buffer area around the pipelines are also shown (grey lines).

Note that in Figure 3, VMS pings of large pulse trawlers (green scatter points) are incidental located inside the 12 mile zone, an area not open for larger trawlers to fish. These points indicate misclassification of fishing activity, owing to low speed steaming activity being picked-up as fishing activity. Given the low density of these points, they are considered to be negligible for the interpretation of the final results.

In the area examined the fishing effort found originated mainly from (pulse) beam-trawlers. The overall mean of total fishing effort per grid cell $(n=16008)$ is 1.9 trawling minutes in 2017 . The mean of the effort of small beamers ( $<300 \mathrm{hp}$ ) is 1.2 minutes per grid cells and 0.7 minutes for large trawlers (>300hp). The frequency distribution of the total fishing effort in 2017 for grid cells around the pipelines and the activity of the two beam-trawler categories is shown in figure 5 . 

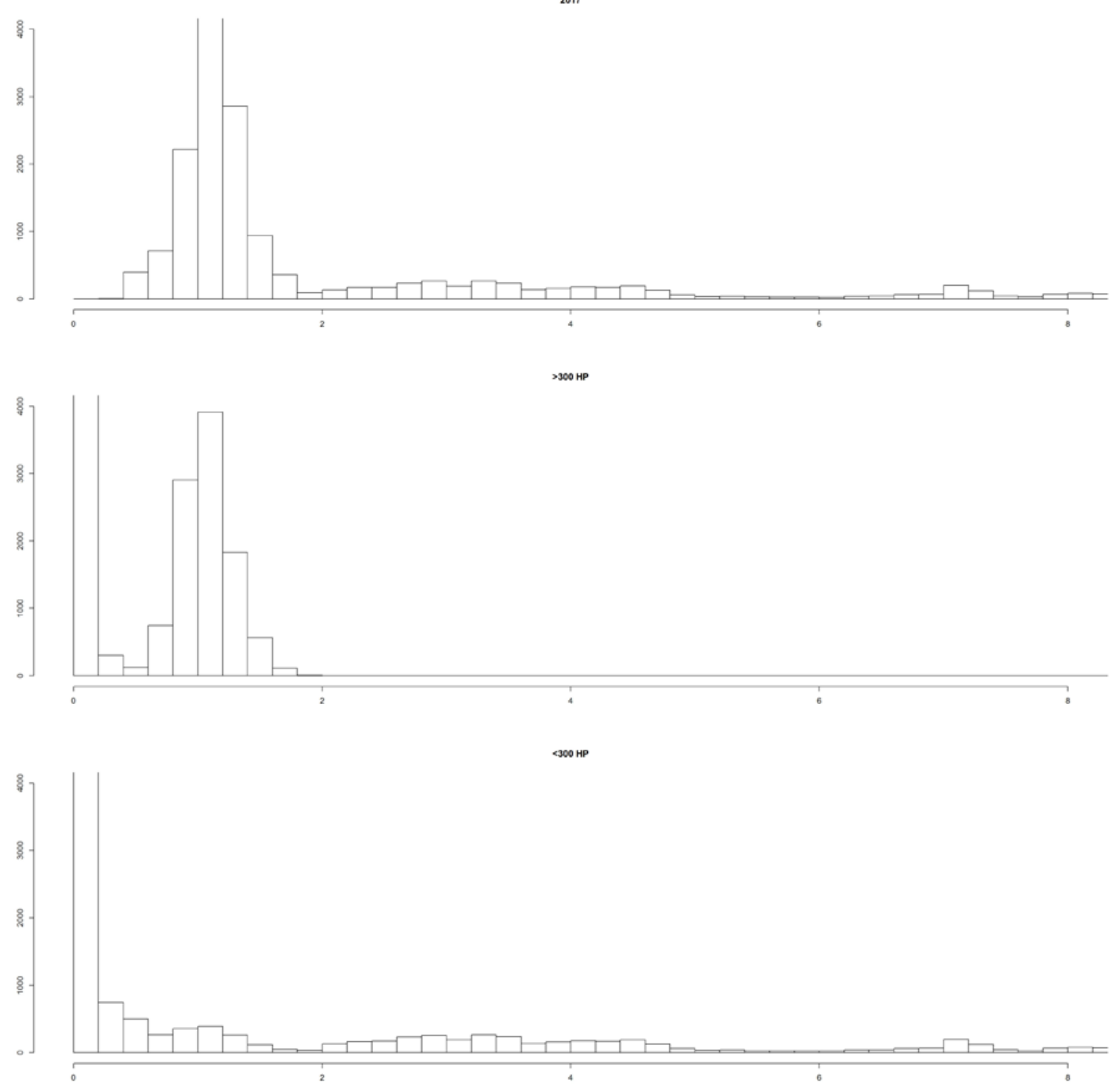

Figure 5. Histograms of (top:) all trawl fishing effort in 2017 (measured in minutes per $68 \mathrm{~m} \times 56 \mathrm{~m}$ grid cell) covering the pipelines trajectories, (below: ) small trawlers ( $<300 \mathrm{hp}$, TBB) and (middle:) large trawlers (>300hp, TBB) in the area around the pipelines. Note that 0-observations disappear when combining small and large TBB.

The overall total trawl fishing effort in 2017 along the pipeline trajectory ranges from 0.4 to 8.7 minutes per grid cell per year and is the result of combining the two fleet types activities. The spatial distribution by trawl effort depends on the vessel size. The smaller trawl vessels are mostly active within the twelvemile coast zone while larger trawlers are banned from this area. The fishing effort of small trawlers ranges from 0.001 to 8.7 minutes and shows 2 modes (1.0-1.2; 2.8-3.4; 7.0-7.2 min.). The fishing effort of large beam-trawlers ranges from 0 to 1.8 minutes and shows one mode (1.0-1.2).

Fishing intensity for large and small trawlers is shown in Figure 6. Here, trawling speed and trawl width is taken into account. The smaller trawl vessels fish at lower speeds (around 3 knots) with gears of approximately $9 \mathrm{~m}$ wide. Shrimp trawlers fish with nets of approximately 19 meter wide. The larger beam-trawl vessels fish at higher speeds (around 6knots) with gears of approximately $24 \mathrm{~m}$ wide. Therefore, fishing intensity does not scale similar to fishing effort. Fishing intensity is highest in the area where small shrimp trawlers are active. The fishing effort figure (Figure 3 ) showed that more effort is allocated by the smaller beam-trawlers and thereby showing a markedly different pattern. Fishing intensity ranged between $\sim 0.2$ to 3.4 times per year. The highest fishing intensity, 3.4 times per year, originate from the shrimp trawling near the coast. In other areas grid surfaces of $68 \mathrm{~m} \times 56 \mathrm{~m}$ was less: max 1.5 times per year for small trawlers and max 2.3 times per year for large trawlers. North Sea wide, fishing intensities up to 10 times a year are recorded while commonly intensities around 5 times a year are measured. 

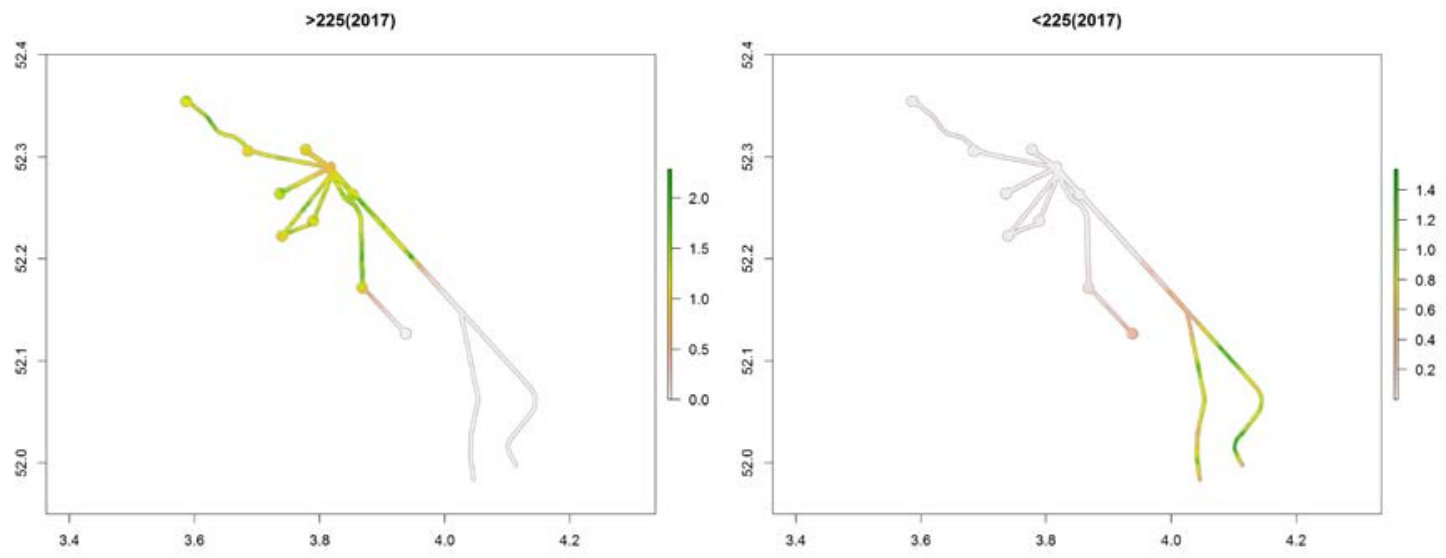

Figure 6. Fishing intensity grid-map of [ left] large bottom trawlers end small trawlers in 2017. The grid cell dimensions are $68 * 56 \mathrm{~m}$ and the colour indicates the fishing intensity in number of times a full grid cell has been trawled (see palette). The buffer area around the pipelines are also shown (grey lines). 


\section{Conclusions and recommendations}

The results from this study show that the fishing activity in 2017 of the beam-trawl fleet are most relevant in the study area, and that fishing activity of otter trawlers, seines and dredges is minimal. The beam-trawlers account for $95 \%$ of all fishing effort in the study area. From a risk perspective, these gears may be more important than otter trawlers or seines too, as they tow heavy gears over the seafloor while otter trawlers and seines tow much smaller metal plates or clumps over the seabed, limiting the amount of pipeline surface they can damage. Similarly, the beam-trawlers may be further divided into vessels operating traditional beam-trawlers, pulse-trawlers, sumwing or chain-mat trawlers. No information is available however on how much damage a small beam-trawl, a large beam-trawl or otter trawl gear would have on a pipeline. For this reason, all gears are treated similarly when expressing fishing effort indicators.

The indication of VMS pings in the figures, clearly show that no obvious avoidance strategy for pipelines is in place. The distribution of VMS pings in close vicinity of the pipelines is similar to areas further away from the pipelines. No direct 'attraction' of fishing activity to pipelines could be observed either, but clear indications of this would require further in-depth analyses. 


\section{Quality Assurance}

Wageningen Marine Research utilises an ISO 9001:2008 certified quality management system (certificate number: 187378-2015-AQ-NLD-RvA). This certificate is valid until 15 September 2018. The organisation has been certified since 27 February 2001. The certification was issued by DNV Certification B.V.

Furthermore, the chemical laboratory at IJ muiden has NEN-EN-ISO/IEC 17025:2005 accreditation for test laboratories with number L097. This accreditation is valid until $1^{\text {th }}$ of April 2021 and was first issued on 27 March 1997. Accreditation was granted by the Council for Accreditation. The chemical laboratory at IJ muiden has thus demonstrated its ability to provide valid results according a technically competent manner and to work according to the ISO 17025 standard. The scope (L097) of de accredited analytical methods can be found at the website of the Council for Accreditation (www.rva.nl).

On the basis of this accreditation, the quality characteristic $\mathrm{Q}$ is awarded to the results of those components which are incorporated in the scope, provided they comply with all quality requirements. The quality characteristic $\mathrm{Q}$ is stated in the tables with the results. If, the quality characteristic $\mathrm{Q}$ is not mentioned, the reason why is explained.

The quality of the test methods is ensured in various ways. The accuracy of the analysis is regularly assessed by participation in inter-laboratory performance studies including those organized by QUASIMEME. If no inter-laboratory study is available, a second-level control is performed. In addition, a first-level control is performed for each series of measurements.

In addition to the line controls the following general quality controls are carried out:

- Blank research.

- Recovery.

- Internal standard

- Injection standard.

- Sensitivity.

The above controls are described in Wageningen Marine Research working instruction ISW 2.10.2.105. If desired, information regarding the performance characteristics of the analytical methods is available at the chemical laboratory at IJ muiden.

If the quality cannot be guaranteed, appropriate measures are taken. 


\section{References}

Poos, J.J. and Rijnsdorp, A. D. 2007. The dynamics of small-scale patchiness of plaice and sole as reflected in the catch rates of the Dutch beam trawl fleet and its implications for the fleet dynamics. Journal of Sea Research, 58: 100-112.

Niels Hintzen \& Marcel Machiels, 2017. Fishing activity near offshore pipelines; . Wageningen, Wageningen Marine Research (University \& Research centre), Wageningen Marine Research report reportnumber C016/18. 19 pp.

Hintzen, N. T., Piet, G. J., and Brunel, T. 2010. I mproved estimation of trawling tracks using cubic Hermite spline interpolation of position registration data. Fisheries Research, 101: 108-115. 


\section{Justification}

Report C016/18

Project Number: 4311000005-9

The scientific quality of this report has been peer reviewed by a colleague scientist and a member of the Management Team of Wageningen Marine Research

Approved:

Dhr. N.T. Hintzen

Onderzoeker

Signature:

Date:

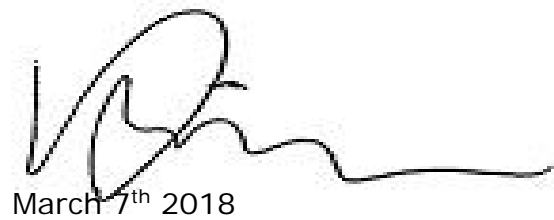

Approved:

Drs. J. Asjes

Manager integration

Signature:

Date:

Mareh $7^{\text {th }} 2018$ 
Wageningen Marine Research

T +31 (0)317480900

E: marine-research@wur.nl

www.wur.eu/marine-research

Visitors' address

- Ankerpark 27, 1781 AG Den Helder

- Korringaweg 5, 4401 NT Yerseke

- Haringkade 1, 1976 CP IJ muiden
Wageningen Marine Research is the Netherlands research institute established to provide the scientific support that is essential for developing policies and innovation in respect of the marine environment, fishery activities, aquaculture and the maritime sector.

\section{Wageningen University \& Research:}

is specialised in the domain of healthy food and living environment.

\section{The Wageningen Marine Research vision}

'To explore the potential of marine nature to improve the quality of life'

\section{The Wageningen Marine Research mission}

- To conduct research with the aim of acquiring knowledge and offering advice on the sustainable management and use of marine and coastal areas.

- Wageningen Marine Research is an independent, leading scientific research institute

Wageningen Marine Research is part of the international knowledge organisation Wageningen UR (University \& Research centre). Within Wageningen UR, nine specialised research institutes of the Stichting Wageningen Research Foundation have joined forces with Wageningen University to help answer the most important questions in the domain of healthy food and living environment. 